\title{
Cytostasis and morphological changes induced by mifepristone in human metastatic cancer cells involve cytoskeletal filamentous actin reorganization and impairment of cell adhesion dynamics
}

BreeAnn N Brandhagen, Chelsea R Tieszen, Tara M Ulmer, Maria S Tracy, Alicia A Goyeneche and Carlos M Telleria*

\begin{abstract}
Background: Changes in cell shape and plasticity in cytoskeletal dynamics are critically involved in cell adhesion, migration, invasion and the overall process of metastasis. Previous work in our laboratory demonstrated that the synthetic steroid mifepristone inhibited the growth of highly metastatic cancer cells, while simultaneously causing striking changes in cellular morphology. Here we assessed whether such morphological alterations developed in response to cytostatic concentrations of mifepristone are reversible or permanent, involve rearrangement of cytoskeletal proteins, and/or affect the adhesive capacity of the cells.

Methods: Cancer cell lines of the ovary (SKOV-3), breast (MDA-MB-231), prostate (LNCaP), and nervous system ( $(\mathrm{8} 7 \mathrm{MG})$ were exposed to cytostatic concentrations of mifepristone and studied by phase-contrast microscopy. The transient or permanent nature of the cytostasis and morphological changes caused by mifepristone was assessed, as well as the rearrangement of cytoskeletal proteins. De-adhesion and adhesion assays were utilized to determine if mifepristone-arrested and morphologically dysregulated cells had abnormal de-adhesion/adhesion dynamics when compared to vehicle-treated controls.

Results: Mifepristone-treated cells displayed a long, thin, spindle-like shape with boundaries resembling those of loosely adhered cells. Growth arrest and morphology changes caused by mifepristone were reversible in SKOV-3, MDA-MB-231 and U87MG, but not in LNCaP cells that instead became senescent. All cancer cell types exposed to mifepristone displayed greatly increased actin ruffling in association with accelerated de-adhesion from the culture plate, and delayed adhesion capacity to various extracellular matrix components.

Conclusions: Cytostatic concentrations of mifepristone induced alterations in the cellular structure of a panel of aggressive, highly metastatic cancer cells of different tissues of origin. Such changes were associated with re-distribution of actin fibers that mainly form non-adhesive membrane ruffles, leading to dysregulated cellular adhesion capacity.
\end{abstract}

\footnotetext{
* Correspondence: Carlos. Telleria@usd.edu

Division of Basic Biomedical Science, Sanford School of Medicine of The University of South Dakota, 414 East Clark Street, Vermillion, SD 57069, USA
} 


\section{Background}

Originally developed as an anti-glucocorticoid agent in the 1980s, the synthetic steroid mifepristone was also found to modulate the progesterone receptor. This unexpected finding led mifepristone to be rapidly repurposed for its use for early termination of pregnancy. However, aside from this most common usage, mifepristone has been proven effective as a growth inhibitor in endometriosis [1,2], uterine fibroids [3-5], and benign cases of meningioma [6]. In relation to cancer cell growth, mifepristone was shown to have antiproliferative effects in cervical [7], breast (reviewed in [8]), endometrial [9-12], ovarian [13-17], gastric [18] and prostate cancer cells [19,20]. In mice with spontaneous lung cancer or leukemia, mifepristone improved quality of life and longevity $[21,22]$. Also, mifepristone given daily to case-study patients with widely metastatic thymic, renal, colon, or pancreatic cancers no longer responding to chemotherapy significantly improved patient quality of life [23]. As early as 1998, the suggestion of the use of mifepristone as a therapeutic option for highly aggressive, metastatic cancers was introduced [24]. However, since then there has been little investigation pursued in this subject area.

Previous work in our laboratory demonstrated that mifepristone: i) arrests the growth of ovarian cancer cells by inhibiting DNA synthesis and halting progression of the cell cycle at the $\mathrm{G}_{1}-\mathrm{S}$ transition [17]; ii) prevents repopulation of remnant ovarian cancer cells when added after platinum or platinum/taxane therapies [15,25]; and iii) has growth inhibitory effects on various cell types representing aggressive cancers of the prostate, breast, nervous system, and bone [26]. Of particular interest in this previous study [26] was the observation that the cells were not only growth inhibited in response to mifepristone, but that they also displayed major changes in their morphological features.

Changes in cellular structure are a consequence of the rearrangement of cytoskeletal proteins, and are critically involved in adhesion turnover and polarized cell migration required for the success of the metastatic process $[27,28]$. In this work we studied whether mifepristone-induced variations in morphology, while cells undergo cytostasis, are dependent on the continuous presence of the drug, and whether there is an association between cytostasis, redistribution of filamentous actin (F-actin) and tubulin filaments, and altered adhesion capacity to extracellular matrix proteins. We report that mifepristone-induced cytostasis and morphological changes were comparable across a panel of different cancer cell lines, with cells developing a thin cytoplasm with neurite-like protrusions. Mifepristone also impacted the distribution of cytoskeletal actin fibers, with increased concentrations in membrane ruffles, and of tubulin filaments mainly allocating to the neurite-like cellular extensions. These observations were associated with an overall impairment in the dynamics of the adhesive capacity of the cells manifested by accelerated detachment when the drug was applied to adherent cells, and impaired attachment of cells that were pre-treated with the drug and then allowed to adhere to extracellular matrix proteins in drugfree media. These results provide evidence supporting a potential role of mifepristone in altering the metastatic capacity of cancer cells.

\section{Methods}

\section{Cell culture and in vitro exposure to mifepristone}

The human ovarian carcinoma cell line SKOV-3, the human breast carcinoma cell line MDA-MB-231, the human glioblastoma cell line U87MG, and the human prostate carcinoma cell line LNCaP were obtained from the American Type Culture Collection (ATCC, Manassas, VA) and cultured as previously detailed [26]. Treatment of the cells with mifepristone (Sigma Chemical Company, St. Louis, MO) used a 20,000 $\mu \mathrm{M}$ stock solution of the drug in DMSO (Mediatech, Herndon, VA). The maximal concentration of DMSO in medium was $0.15 \%(\mathrm{v} / \mathrm{v})$. The final working concentrations of mifepristone were $23.5 \mu \mathrm{M}$ for SKOV-3 cells, $30 \mu \mathrm{M}$ for MDA-MB-231 cells, $20 \mu \mathrm{M}$ for U87MG cells, and $20 \mu \mathrm{M}$ for LNCaP cells. All cells were cultured at $37^{\circ} \mathrm{C}$ in a humidified atmosphere in the presence of $5 \% \mathrm{CO}_{2}$. The human fibroblast cell line WI-38 used as negative control of cell senescence was obtained from ATCC and was maintained in DMEM (Mediatech) supplemented with 10\% FBS (Atlanta Biologicals, Lawrenceville, GA), $10 \mathrm{mM}$ HEPES, $4 \mathrm{mM}$ L-glutamine (Sigma), $1 \mathrm{mM}$ sodium pyruvate (Mediatech), 100 IU penicillin (Mediatech), and $100 \mu \mathrm{g} / \mathrm{ml}$ streptomycin (Mediatech). All cells were cultured at $37^{\circ} \mathrm{C}$ in a humidified atmosphere in the presence of $5 \% \mathrm{CO}_{2}$.

\section{Time-course of morphology}

Cells were seeded in 6-well plates at a density of 100,000 cells per well and allowed $24 \mathrm{~h}$ for attachment. Using previously established cytostatic doses of mifepristone (SKOV-3: $23.5 \mu \mathrm{M}$, MDA-MB-231: $30 \mu \mathrm{M}$, U87MG: $20 \mu \mathrm{M}$, LNCaP: $20 \mu \mathrm{M})$ [26]), treatment was performed for $72 \mathrm{~h}$, during which morphology changes were assessed by phase contrast microscopy. Images of vehicle and mifepristonetreated cells were taken every $12 \mathrm{~h}$ throughout the experimental period using a Zeiss Axiovert M200 inverted microscope with a phase contrast objective (Carl Zeiss, Thornwood, NY). Additionally, SKOV-3 cells were grown in chamber slides at a concentration of 10,000 cells per well and subjected or not to treatment with mifepristone. At the end of incubation, the cells were fixed with $4 \%$ paraformaldehyde (Sigma) and stained with hematoxylin (Sigma).

\section{Reversal of cell proliferation and morphology}

In order to determine the long-term effect of mifepristone treatment, cell morphology was assessed after removal of 
treatment media. After $72 \mathrm{~h}$ of treatment, mifepristonecontaining media was removed, and media for all cells was replaced with control media. Phase contrast images were taken at $0 \mathrm{~h}, 12 \mathrm{~h}, 24 \mathrm{~h}, 48 \mathrm{~h}$, and $72 \mathrm{~h}$ after mifepristone withdrawal to observe cell morphology. In addition to images taken at each time-point, cell number and viability were determined using the Guava EasyCyte Mini microcapillary cytometer (Guava Technologies, Hayward, CA). Samples were collected at the beginning of the experiment, for vehicle and mifepristone-treated cells after $72 \mathrm{~h}$ of treatment, and at each time-point after treatment withdrawal. Triplicate wells were trypsinized, the cells pelleted by centrifugation at $500 \mathrm{~g}$ for 5 minutes, and resuspended in an appropriate volume of PBS. A 1:10 (v/v) dilution of cell suspension and ViaCount reagent (Guava Technologies) was prepared for each sample. The data were acquired and analyzed using the CytoSoft 4.1 software (Guava Technologies).

\section{Senescence Associated (SA)- $\beta$-galactosidase staining}

Using 6-well plates, LNCaP cells were plated at a density of 50,000 cells per well. Cells were treated with mifepristone for $72 \mathrm{~h}$ followed by vehicle for 5 days, or vehicle, $5 \%$ charcoal-stripped (CS)-FBS, or 10\% CS-FBS media for 8 days prior to SA- $\beta$-galactosidase staining. Cells were fixed in $0.5 \%$ glutaraldehyde at $4^{\circ} \mathrm{C}$ for $10 \mathrm{~min}$ and then washed three times with PBS. Cells were then incubated for $3 \mathrm{~h}$ with 5-bromo-4-chloro-3-indolyl-beta-Dgalactopyranoside (X-gal) staining solution consisting of $1 \mathrm{mg} / \mathrm{ml}$ X-gal, $40 \mathrm{mM}$ citric acid/sodium phosphate ( $\mathrm{pH}$ 6.0), $5 \mathrm{mM}$ potassium ferricyanide, $5 \mathrm{mM}$ potassium ferrocyanide, $150 \mathrm{mM} \mathrm{NaCl}$, and $2 \mathrm{mM} \mathrm{MgCl}_{2}$. Following incubation, cells were washed briefly with PBS and stored in $100 \%$ methanol for analysis and imaging. Cells that expressed SA- $\beta$-galactosidase were stained blue when viewed using a Zeiss Axiovert M1-Imager (Carl Zeiss) microscope. Senescence was quantified as the number of blue-stained cells per field and expressed as a percent of total number of cells per field and corrected against a negative control. The average of 9 fields per well was calculated, with 3 wells per treatment group. Positive controls for senescence staining were LNCaP cells that had been depleted of steroids by culture in $5 \%$ or $10 \%$ CS-FBS media as reported [29]. The negative control for senescence was a culture of WI-38 fibroblasts maintained in FBS-containing media.

\section{Immunocytochemistry}

All cell lines were plated in 8-well chamber slides at a density of 5,000 cells per well. Cells were allowed to attach for $24 \mathrm{~h}$ before treatment began. Wells were treated with vehicle or media containing mifepristone for $72 \mathrm{~h}$ at doses tailored to induce cytostasis and morphological changes to individual cell lines. Following treatment cells were fixed according to Waterman-Storer et al. [30] to ensure stabilization of microtubules. First, cells were prefixed for $5 \mathrm{~min}$ in a solution of $1 \%$ paraformaldehyde, $0.5 \%$ Triton $\mathrm{X}-100$, prepared in PHEM buffer $[60 \mathrm{mM} \mathrm{Na}$ PIPES, 25mM Hepes, 10 mM EGTA, 4 mM MgSO , pH 7.2]. Next, cells were fixed for $15 \mathrm{~min}$ in a solution of $1 \%$ paraformaldehyde, $0.5 \%$ glutaraldehyde, prepared in PHEM. This was followed by 3 washes with PHEM buffer alone. Finally, any free aldehydes were blocked by $3 \times 5$ min incubations with $1 \mathrm{mg} / \mathrm{ml}$ sodium borohydride. Cells were rinsed with PBS multiple times and stored in $\mathrm{PBS}$ at $4^{\circ} \mathrm{C}$ until staining. Following fixation, cells were incubated with a blocking buffer [PBS, 5\% normal goat serum (NGS), 0.1\% Triton X-100] for $20 \mathrm{~min}$ at room temperature. This was followed by $1 \mathrm{~h}$ incubation with $1 \mu \mathrm{g} / \mathrm{ml}$ of anti-bovine $\alpha$-tubulin, mouse monoclonal antibody (A-11126, Molecular Probes, Eugene, OR). Any unbound antibody was removed by $3 \times 5 \mathrm{~min}$ washes with washing buffer (PBS, 0.1\% Triton X-100). Cells were then incubated at room temperature for $1 \mathrm{~h}$ with $1 \mu \mathrm{g} / \mathrm{ml}$ of Alexa Fluor ${ }^{\circledR} 488$ Goat Anti-Mouse IgG $(\mathrm{H}+\mathrm{L})$ (A-11001, Molecular Probes). From this point onward, cells were protected from light. The unbound secondary antibody was removed with $3 \times 5$ min washes with washing buffer. To access F-actin distribution, cells were incubated with Alexa Fluor ${ }^{\circledR} 594$ phalloidin (Invitrogen, Grand Island, NY). A $6.6 \mu \mathrm{M}$ stock solution of Alexa Fluor ${ }^{\circledR} 594$ phalloidin was diluted with PBS containing $1 \%$ BSA in a 1:40 ratio. Cells were incubated with the phalloidin staining solution for $20 \mathrm{~min}$. Finally, cells were washed multiple times with PBS and mounted using Vectashield ${ }^{\circledR}$ Hard-Set $^{\text {TM }}$ Mounting Medium with DAPI (Vector Laboratories Inc., Burlingame, CA). Cover slips were added and slides were allowed to set at room temperature for $15 \mathrm{~min}$. Slides were then stored at $4^{\circ} \mathrm{C}$, protected from light. Images were taken using a confocal Olympus FV1000 microscope with FluoView ${ }^{\circledR}$ software.

\section{SDS-PAGE and western blotting}

Cells were treated with vehicle or mifepristone for $72 \mathrm{~h}$, after which cultures were trypsinized, stained with trypan blue, and counted using a hemacytometer. Equal numbers of viable vehicle and mifepristone-treated cells were then pelleted, washed twice with PBS, and snap frozen followed by storage at $-80^{\circ} \mathrm{C}$. Whole cell extracts were obtained, protein quantitated, separated by SDS-PAGE, electrotransferred to PVDF membranes, and then probed for $1 \mathrm{~h}$ at room temperature using primary antibodies against $\alpha$-tubulin (A-11126; 1:1,000; Molecular Probes), $\beta$-actin (clone AC-15; 1:10,000; Sigma), or GAPDH (ab94985; 1:8,000; Abcam Inc., Cambridge, MA).

\section{De-adhesion assay}

Cells were first grown to 50\% confluence in 6-well plates, and then treated with vehicle or mifepristone-containing 
media for $72 \mathrm{~h}$. Following treatment, cells were exposed to $0.025 \%$ trypsin/ $0.265 \mathrm{mM}$ EDTA for $30 \mathrm{sec}, 2 \mathrm{~min}$ or 4 min. Detached cells were removed with a washing of PBS. Cells remaining adhered were fixed with $100 \%$ methanol, stained with crystal violet, and quantified using bright field microscopy. Cell adhesion was expressed as percent of adherent cells for each of the times of exposure relative to the adhesion measured in a culture not exposed to tryp$\sin$ (considered to be 100\%).

\section{Adhesion assays}

The first adhesion assay was performed under sterile conditions using the CytoSelect 48-Well Cell Adhesion Assay (CBA-070, Cell Biolabs Inc., San Diego, CA). Briefly, the adhesion plates containing various extracellular matrix components (fibronectin, collagen I, collagen IV, fibrinogen, or laminin) were allowed to warm up at room temperature for $10 \mathrm{~min}$. Cell suspensions were then prepared containing $1 \times 10^{6}$ cells per $\mathrm{ml}$ in serum-free media with or without mifepristone; $150 \mu \mathrm{l}$ of each cell suspension was added to the appropriate wells and the plates were incubated for 60 min at $37^{\circ} \mathrm{C}$ in a humidified atmosphere in the presence of $5 \% \mathrm{CO}_{2}$. The media was discarded from each well and all wells were washed 4-5 times with $250 \mu \mathrm{l}$ PBS. PBS was removed and $200 \mu \mathrm{l}$ of the provided cell stain solution was added to each well. The plates were incubated for $10 \mathrm{~min}$ at room temperature. After incubation, the cell stain solution was removed and each well was washed 4-5 times with $500 \mu \mathrm{l}$ of deionized water. The final wash was discarded and wells were allowed to air dry. Next, $200 \mu \mathrm{l}$ of provided extraction solution was added to each well and the plates were incubated for $10 \mathrm{~min}$ on an orbital shaker at room temperature. Finally, $150 \mu \mathrm{l}$ of each sample was transferred to 96-well microtiter plates and the optical density at 540 $\mathrm{nm}$ was measured using a Titertek Multiskan MCC/340 Microplate Reader II (Dupont, Labsystems, Finland).

When adhesion to fibronectin was further studied, cells were cultured in the presence of $20 \mu \mathrm{M}$ mifepristone for $72 \mathrm{~h}$ or left untreated in controls. The cells were trypsinized and incubated in suspension for $20 \mathrm{~min}$ to allow recovery from trypsinization. Thereafter, 100,000 cells were placed per $35 \mathrm{~mm}$ diameter plates that had been pre-coated with $0.1 \%$ fibronectin (Sigma), and were incubated for various times. Cells were fixed with methanol and stained with crystal violet. Counting was achieved under a microscope by recording number of adherent cells per $20 \mathrm{X}$ microscopic field.

\section{Statistical analysis}

Data processing and statistical analysis were performed using GraphPad Prism (GraphPad Prism Software, Inc., San Diego, CA). All data are represented as means \pm SEM, and statistical significance was defined as $P<0.05$. To compare among experimental groups, one-way ANOVA followed by the Tukey's multiple comparison test or two-way ANOVA followed by the Bonferroni's multiple comparison test were used as appropriate. To study significant differences between two groups, the Student's $t$-test was used.

\section{Results \\ Cytostatic concentrations of mifepristone cause morphological changes in cancer cell lines of the ovary, breast, prostate, and nervous system}

In a previous study we made the serendipitous observation that when cancer cells of various tissues of origin were exposed to concentrations of mifepristone that inhibited their growth [26], the cells displayed major changes in shape when compared to untreated growing cells. In the present work, highly aggressive cell lines representing cancers of the ovary, breast, prostate, and nervous system were selected for further analysis. Treatment with a previously tailored cytostatic dose of mifepristone for each cell line was administered for a period of $72 \mathrm{~h}$, and images were taken using phase contrast microscopy every $12 \mathrm{~h}$. At the end of the incubation period the number of cells was significantly reduced in mifepristone-treated wells when compared to their vehicletreated counterparts (Figure 1A). The growth inhibitory effect of mifepristone was confirmed in microscopic images showing fewer cells present in mifepristone-treated cultures after $72 \mathrm{~h}$ incubation (Figure 1B). Phase contrast views across the panel of cell lines reveal that mifepristonetreated cells display a long, thin, spindle-like shape with boundaries resembling those of cells loosely adhered. The neurite-like extensions induced by mifepristone appear to reach out to other cells in the field (Figure 1B). The morphological changes induced by mifepristone began to be appreciated within 24-48 h of treatment (Additional file 1: Figure S1). Further details of thinning of the cytoplasm can be clearly appreciated upon hematoxylin staining in SKOV-3 cells that were exposed to $20 \mu \mathrm{M}$ mifepristone for $72 \mathrm{~h}$, when compared to vehicle-treated controls (Additional file 2: Figure S2). The morphological changes caused by mifepristone in all cell lines also occurred when cells were cultured at high density (results not shown). This confirmed the intrinsic effect of mifepristone on cell shape, and that observed morphological changes were not a result of perceived bias, owing to the reduced cellular densities commonly observed in cultures exposed to mifepristone as a consequence of the cytostatic effect of the steroid.

\section{Cellular proliferation and morphological changes are reversible upon removal of mifepristone in all cell lines except for LNCaP prostate cancer cells that undergo cellular senescence}

To determine the long-term effect of mifepristone on cell proliferation and morphology, each cell line was cultured 


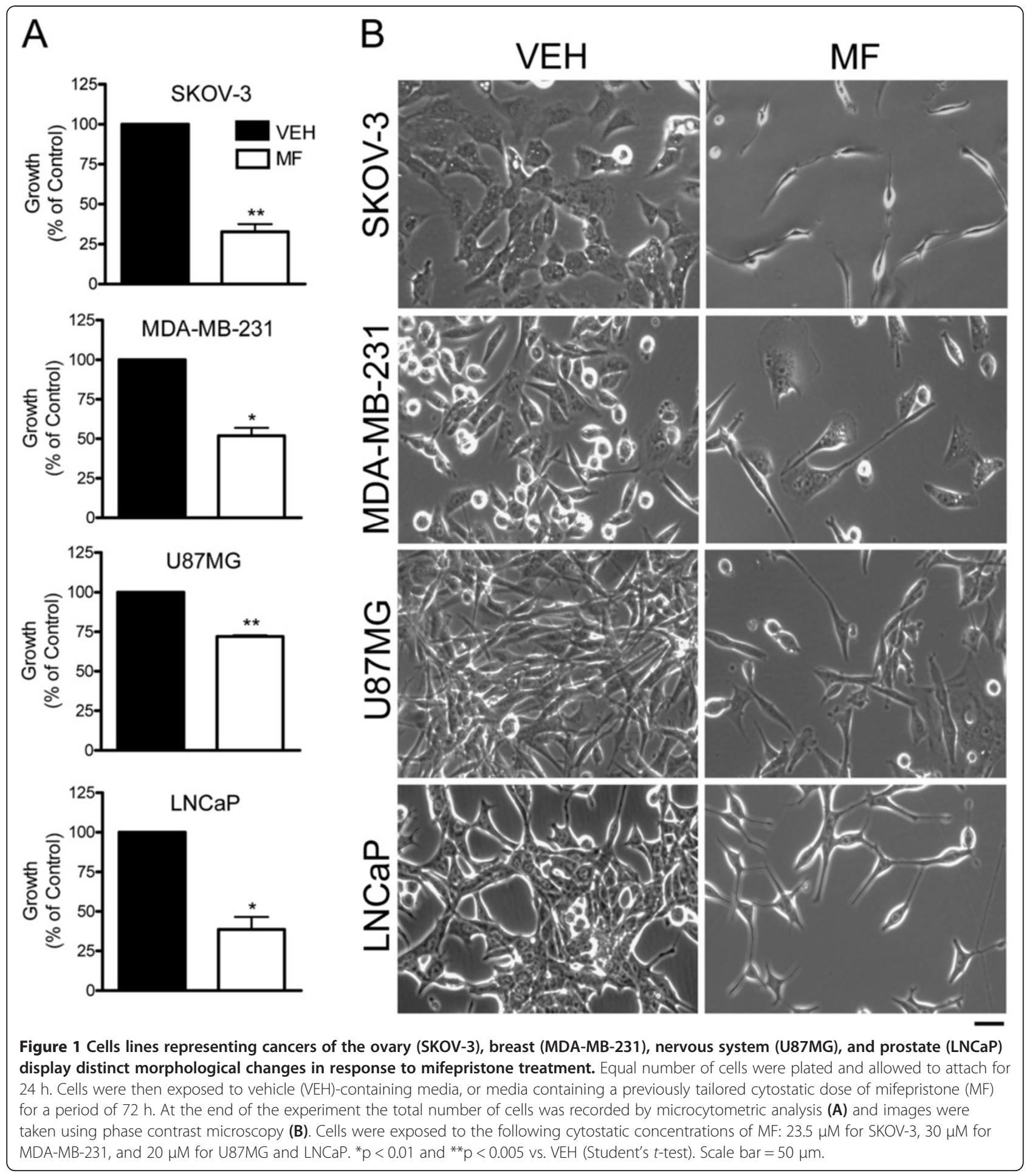

in the presence of vehicle or mifepristone for $72 \mathrm{~h}$. Thereafter, mifepristone was removed from the cultures and replaced with media lacking the drug for 5 days. Subsequently, cultures were imaged and cell number was determined every $24 \mathrm{~h}$ to monitor for reversal of morphology and proliferation. While the proliferation of SKOV-3,
MDA-MB-231, and U87MG cells remained relatively slow 1-2 days post-treatment, by day 3 after mifepristone withdrawal, cultures were proliferating at the same rate as cultures never treated with the synthetic steroid (Figure 2A-C and Figure 3A-C). Of note is that mifepristone pretreated cultures, when re-growing upon drug withdrawal, did not 


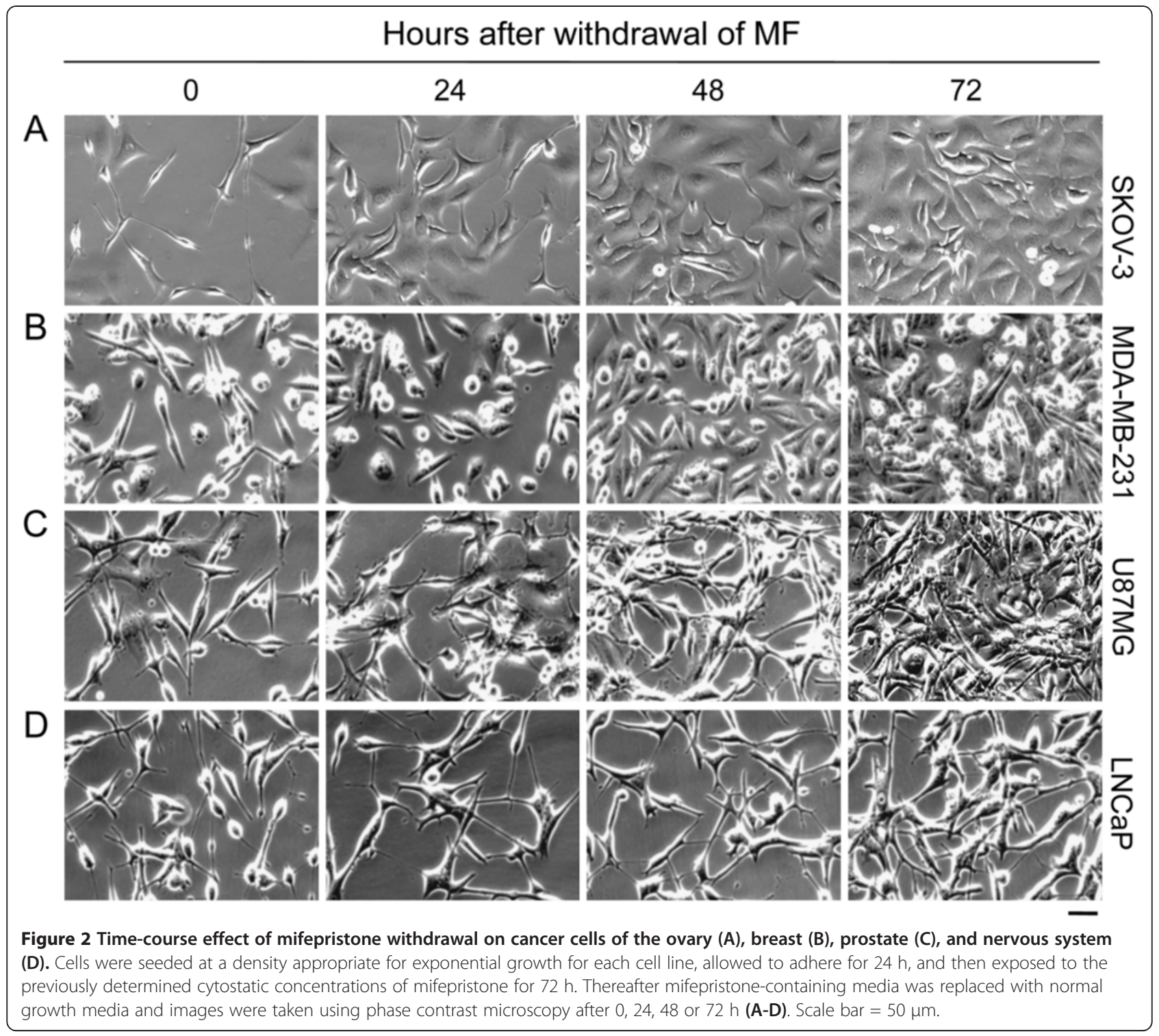

exceed the proliferation rate of their vehicle counterparts, but returned to a comparable doubling time (Figure 3A-C). In contrast, release of $\mathrm{LNCaP}$ cells from mifepristone treatment did not result in a return to normal proliferation (Figure 2D). Instead, mifepristone-pretreated LNCaP cultures failed to resume growth and remained with a steady state cell number through 5 days of normal culture conditions, while vehicle cultures increasingly proliferated (Figure 3D). Such regrowth was not observed either when extending the incubation in drug-free media for 9 days (Additional file 3: Figure S3). While LNCaP mifepristonetreated cultures did not resume normal proliferation, the cells did not show signs of lethality either, as indicated by morphological features (Figure 2D) and viability (Figure 3E) comparable to those of untreated cells. To determine whether the lack of growth of $\mathrm{LNCaP}$ cells upon removal of mifepristone is consequence of a permanent cell cycle arrest associated with cellular senescence, we stained mifepristone-pretreated LNCaP cells for SA- $\beta$ galactosidase activity. Results shown in Figure 4A reveal that while cultures not treated with mifepristone display low percentage of SA- $\beta$-galactosidase positive cells, such number remarkably increased in cultures under the presence of mifepristone. The increase in the percentage of SA- $\beta$-galactosidase positive cells induced by mifepristone was similar to that achieved when LNCaP cells were cultured in steroid-deprived medium, a condition reported to induce senescence in this cell line (Figure 4B) [29].

\section{Cytostatic doses of mifepristone dysregulate the} cytoskeletal architecture of cancer cells

To further characterize the morphological changes caused by cytostatic, non-lethal concentrations of mifepristone, the various cancer cell types were cultured in the presence 


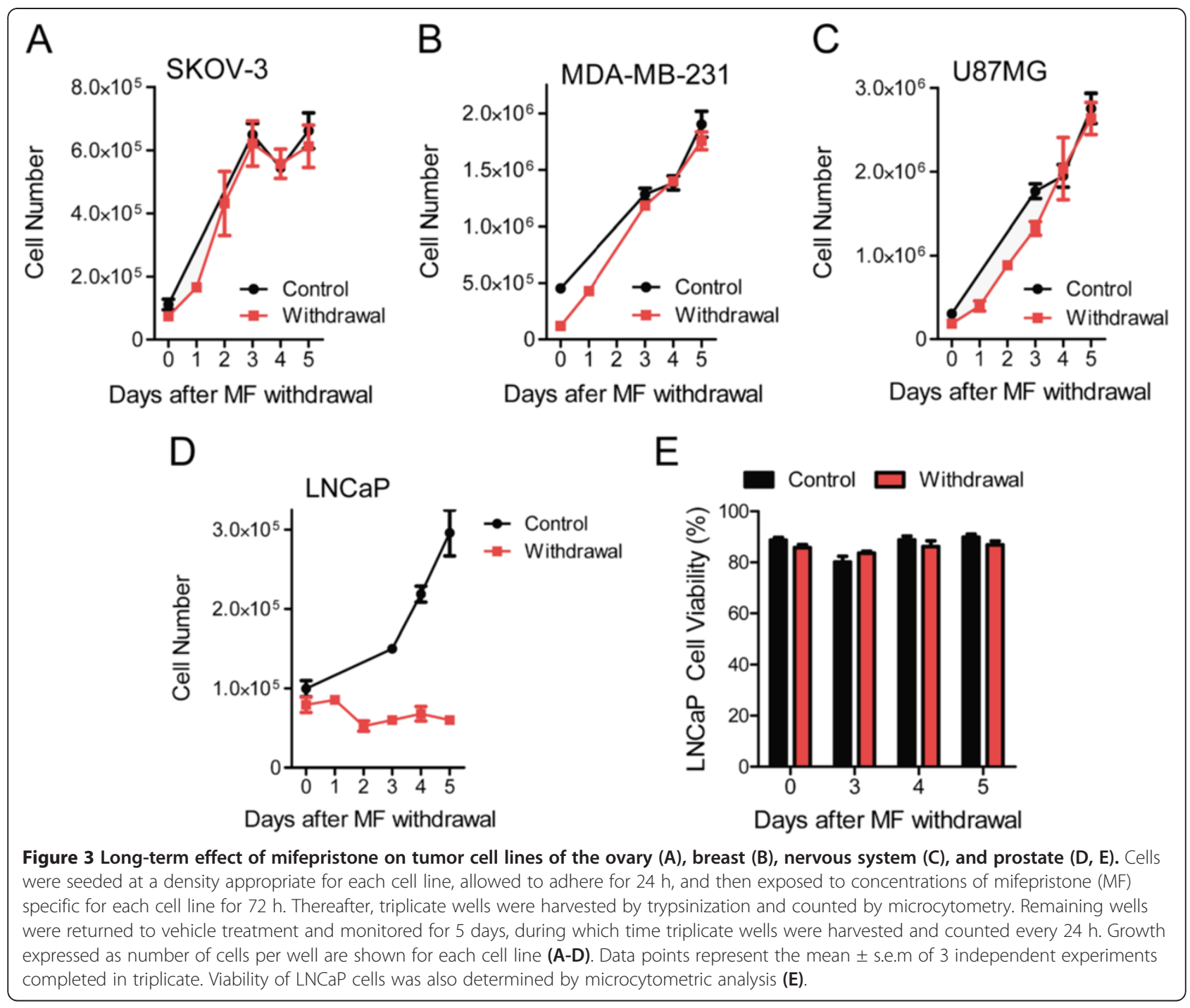

of vehicle or mifepristone for $72 \mathrm{~h}$, and the arrangement of filamentous actin (F-actin) and tubulin filaments contributing to cytoskeletal structure and overall cell morphology were assessed. Figure 5 depicts that mifepristone, in addition to causing changes in overall cell shape, disrupted the organization of both actin fibers and tubulin filaments. Confocal imaging revealed that untreated SKOV-3 cells possess cortical actin, stress fibers, and cell polarity as shown by the presence of lamellipodia (Figure $5 \mathrm{~A}$, left panel). Mifepristone caused a remarkable change in cell shape, loss of cortical actin and stress fibers, and gain of peripheral membrane ruffles rich in polymerized actin (Figure 5A, right panel). In U87MG cells, treatment with mifepristone did not change the distribution of cortical actin substantially, yet it increased the number of peripheral actin ruffles (Figure 5B). MDA-MB-231 breast cancer cells responded to mifepristone with a remarkable increase not only of peripheral actin ruffles, but also of circular dorsal actin ruffles or actin ribbons (Figure 5C). Finally in
LNCaP cells, mifepristone, as in the other cancer cell types, caused an increase in the number of peripheral actin ruffles (Figure 5D). A commonality in all cancer cells under the effect of mifepristone was the increase in the number of membrane actin ruffles (Figure 5E). Tubulin, which in untreated and polarized cells usually arranges around the microtubule-organizing center and the Golgi apparatus [31], was mainly found framing the periphery of the nuclei in control cells; however, in mifepristonetreated cells, tubulin accumulated mainly in the long-thin neurite-like extensions (Figure 5). The complete microscopic fields of the cell cultures from which the images represented in Figure 5 were obtained, can be observed in Additional file 4: Figure S4.

To evaluate whether mifepristone was merely dysregulating the distribution of actin and tubulin or changing their abundance, we assessed the expression levels of one of the isotypes of actin, $\beta$-actin, and one of the isotypes of tubulin, $\alpha$-tubulin. Given that actin and tubulin 


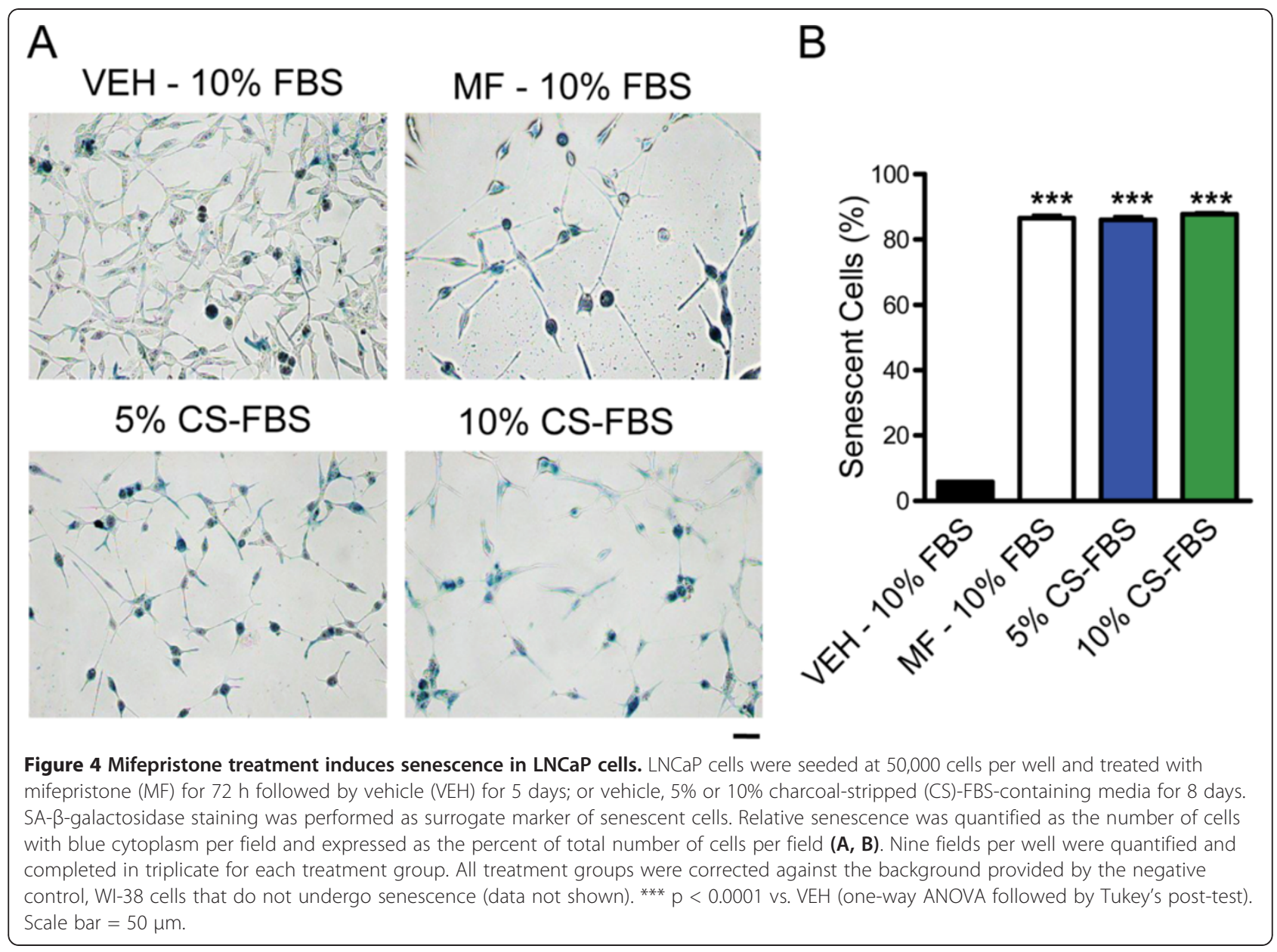

are both commonly used as loading controls in Western blot studies, we sought to evaluate any differences in their expression by loading lysates obtained from an equal number of vehicle or mifepristone-treated cells. Membranes were immunoblotted for $\beta$-actin, $\alpha$-tubulin, and GAPDH, which was used as protein loading control. Densitometry analysis was performed and protein levels expressed as the ratio of $\beta$-Actin/GAPDH (Additional file 5: Figure S5A) or $\alpha$-Tubulin/GAPDH (Additional file 5: Figure S5B). Mifepristone did not significantly change the expression levels of either $\beta$-actin or $\alpha$-tubulin in any cell line, suggesting that the action of mifepristone is limited to dysregulating the distribution of the proteins and, consequently, the overall architecture of the cytoskeleton

\section{Effect of mifepristone on cellular de-adhesion and adhesion dynamics}

One commonality in the cancer cells that were treated with cytostatic doses of mifepristone was the increased density of membrane actin ruffles along the surface of the cells (Figure 5). Actin ruffles are sheet-like membrane protrusions that do not adhere to the substratum and increase in number whenever the adhesion of a cell to the substratum is not optimal [32,33]. Consequently, we first investigated whether cells that are already attached, once treated with mifepristone, are loosely adhered and, secondly, whether pre-treatment with mifepristone affected the adhesion capacity of cells to extracellular matrixcoated surfaces. To answer the first question, we assessed the capability of cells to remain attached under treatment with mifepristone via a cell de-adhesion assay. The cells were plated at equal densities and treated with mifepristone for $72 \mathrm{~h}$, at which point they were exposed to a very low concentration of trypsin/EDTA for short periods of time; these conditions do not allow for the optimal detachment of cells that are well adhered. All cells that detached from the plate were removed, and those remaining were fixed, stained, and counted. In all cases, cells pre-treated with mifepristone, having had they morphology altered, detached at a significantly faster rate than those untreated. This effect was seen as early as $30 \mathrm{sec}$ following induction of de-adhesion in all cell lines (Figure 6A-D). Figure 6E shows a representative field of U87MG cells remaining in the plate after $4 \mathrm{~min}$ of induction of de-adhesion. Mifepristone-pretreated cells, which are scarce in the culture field, still show their thin and elongated neurite-like 


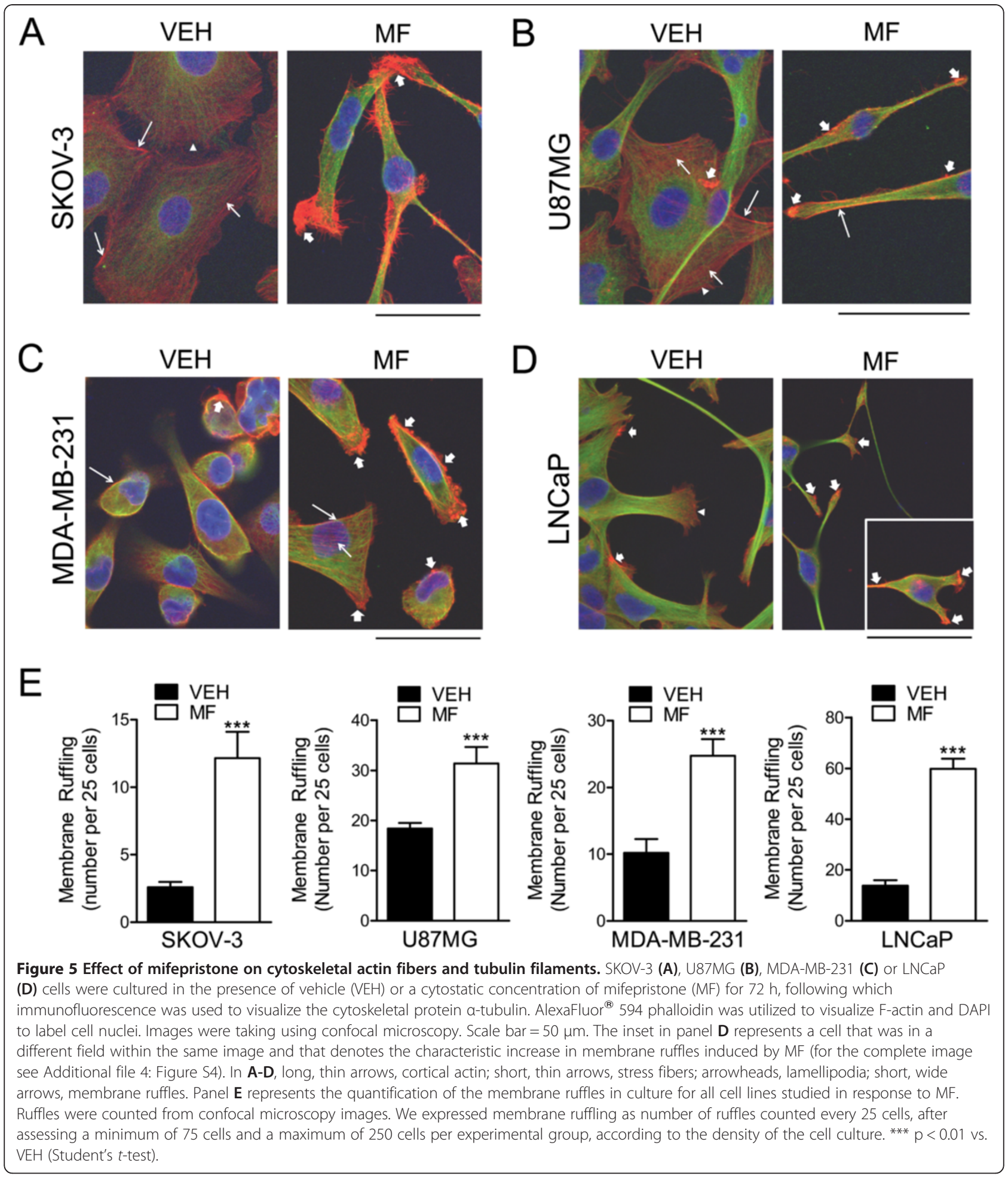

extensions, a consequence of mifepristone action (Figure 6E, right panel). In contrast, vehicle-treated cells exposed to the same de-adhesion conditions as their mifepristone-treated counterparts, were less sensitive to the mild trypsinization procedure, and depict normal morphology (Figure 6E, left panel).
To assess whether mifepristone impairs the capacity of cancer cells to adhere to extracellular matrix, cells were pre-treated for $72 \mathrm{~h}$ with or without a cytostatic concentration of mifepristone, trypsinized, and re-plated in commercially available plates that had been pre-coated with an array of extracellular matrix proteins including 


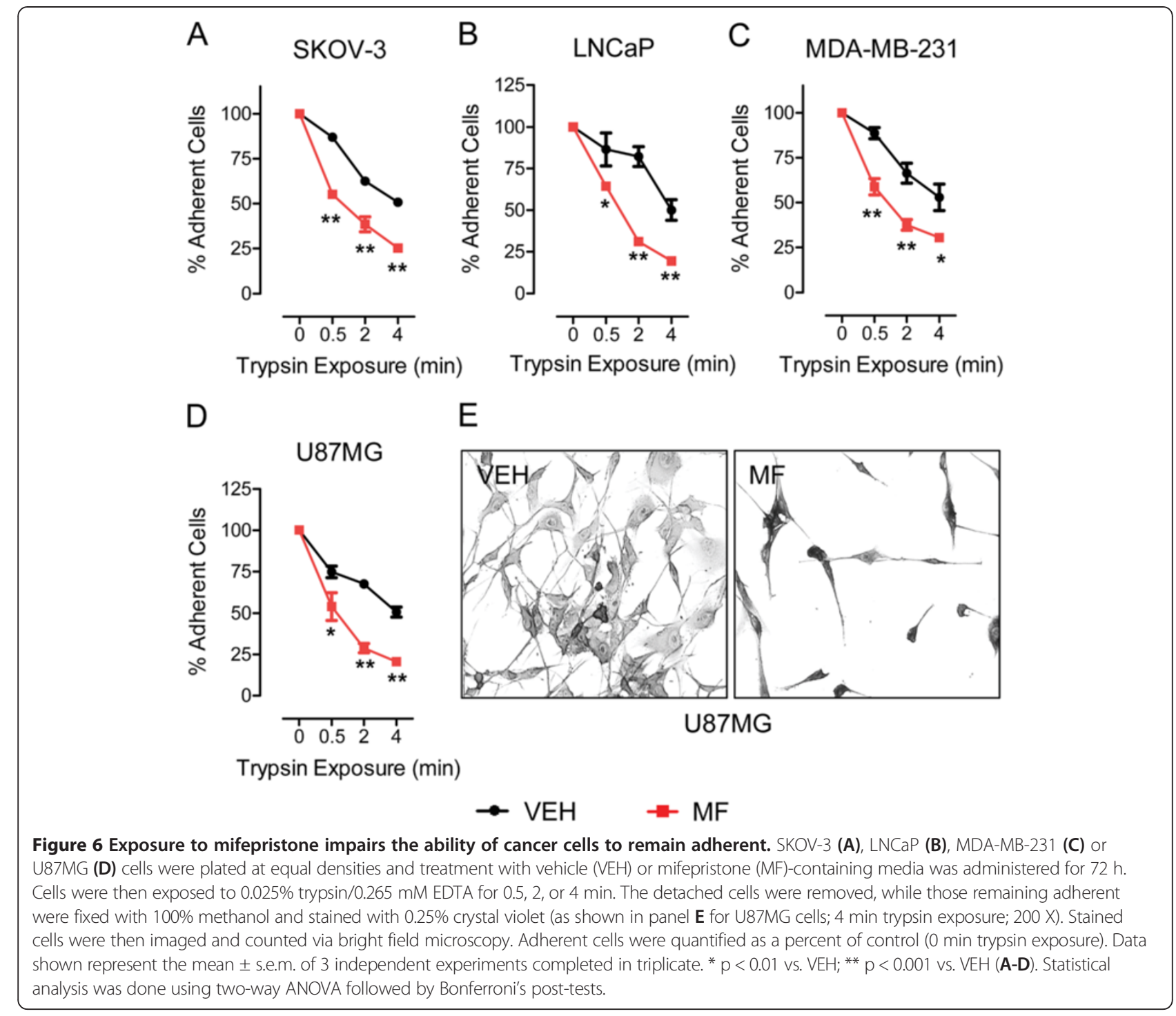

fibronectin, collagen I, collagen IV, laminin or fibrinogen. Cells were allowed $1 \mathrm{~h}$ to adhere, except for LNCaP cells that underwent adhesion for $24 \mathrm{~h}$. Thereafter, the cells were stained and optical density (OD) was measured. All cell lines showed different kinetics of adhesion to the substrates offered, as observed by the different ranges of OD detected (Figure 7A-D). Mifepristone pretreated cells, in all cell lines studied, had diminished adhesion to each one of the surfaces within a particular time-frame (Figure 7A-D). Data presented in Figure 7 represents one experiment that was repeated three times with a similar trend, yet we found variability in the overall adhesion capacity of the cell preparations from one experiment to the next. Consequently we semi-quantitated the data from three experiments; we defined a strong inhibitory effect of mifepristone when there was a decrease in OD reading of more than $50 \%$ as compared to vehicle treated cells; similarly, a slight inhibitory effect was defined as a $10-50 \%$ of OD decrease. Finally, a decrease in OD reading of less than $10 \%$ was considered as no effect. In all cell lines, either a slight or a strong inhibitory effect of mifepristone on cell adhesion was observed along the three independent experiments (Additional file 6: Table S1).

To confirm the impairment of mifepristone-pretreated cells to adhere to an extracellular matrix-related protein, an equal number of either vehicle-pretreated or mifepristonepre-treated SKOV-3 cells were incubated at $37^{\circ} \mathrm{C}$ for various times $(0.5,1$, or $2 \mathrm{~h})$ on plates that had been pre-coated with fibronectin. Thereafter, the cultures were washed to remove the non-adherent cells, whereas the cells that had already attached to the plate at each time point were fixed with methanol, stained with crystal violet, and their number was quantified per microscopic field. The results shown in Figure $7 \mathrm{E}$ clearly indicate that pretreatment with mifepristone significantly delayed the 

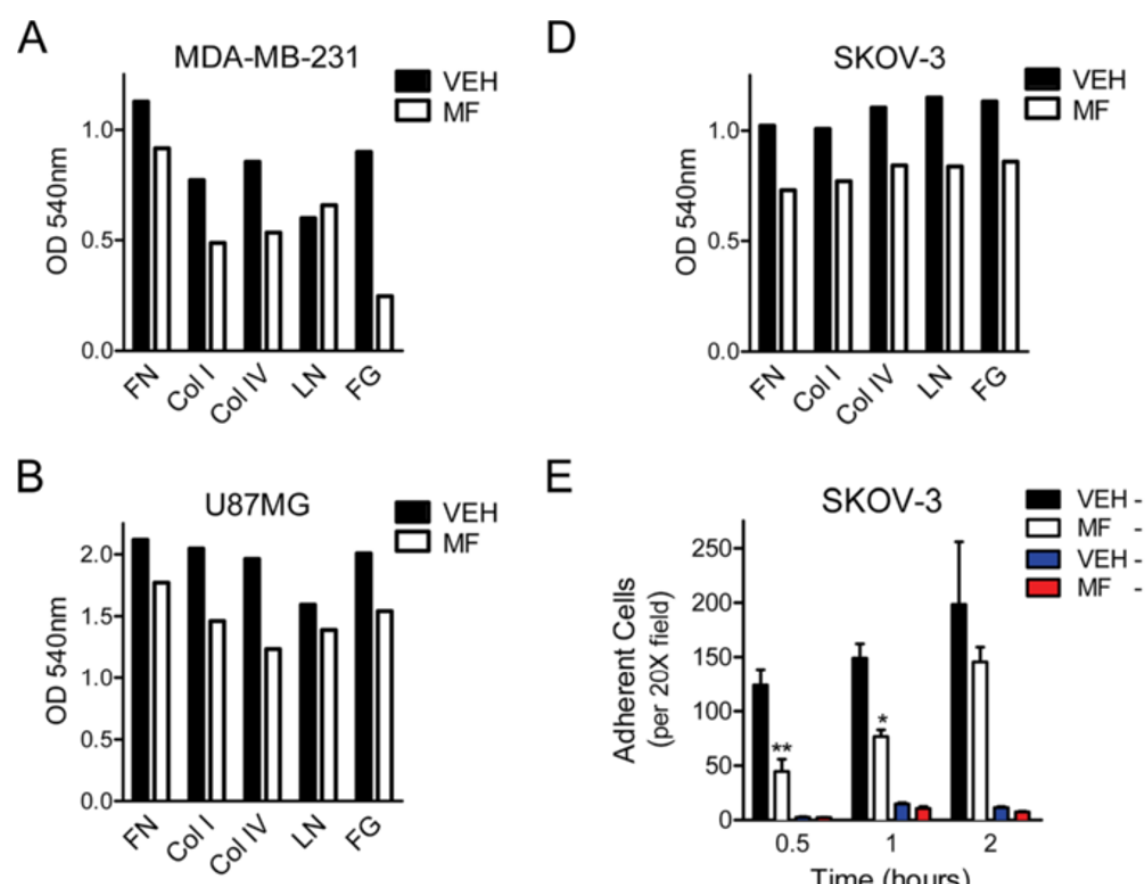

E
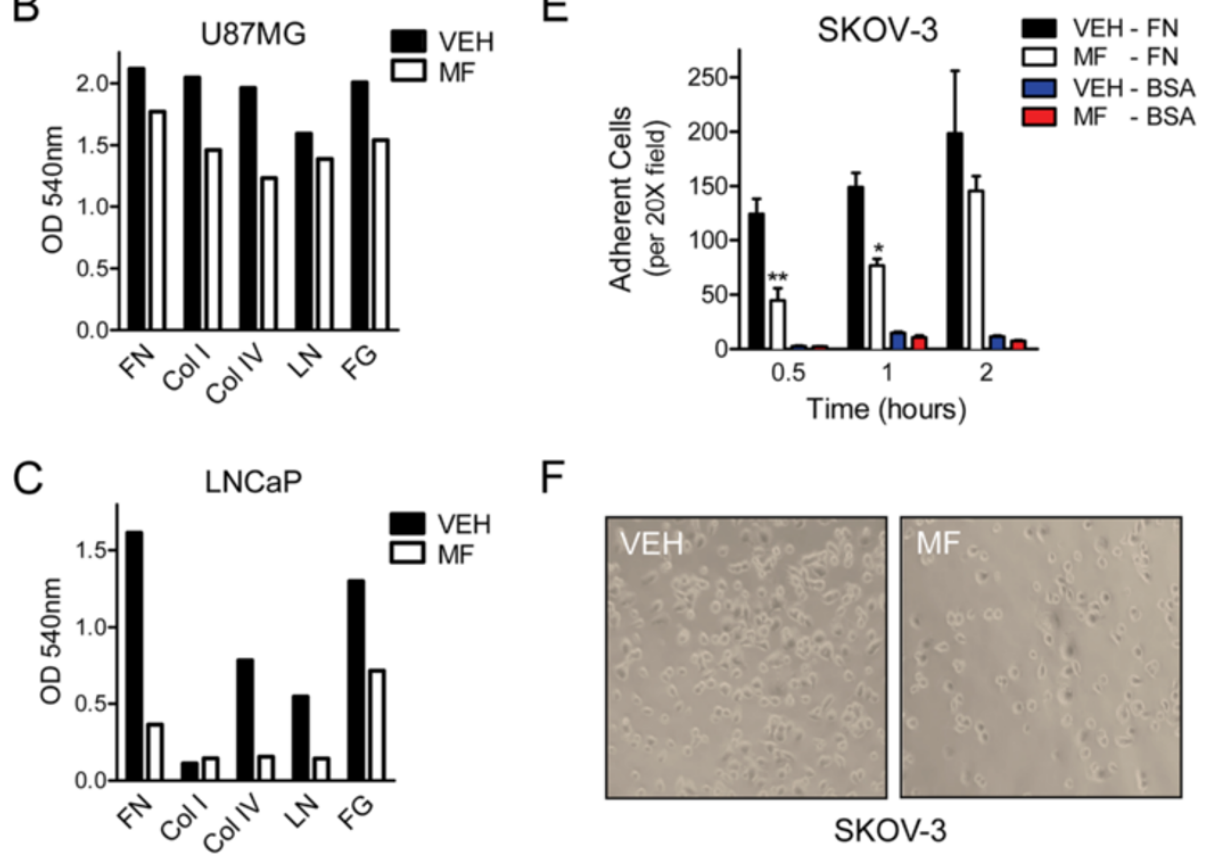

$\mathrm{F}$

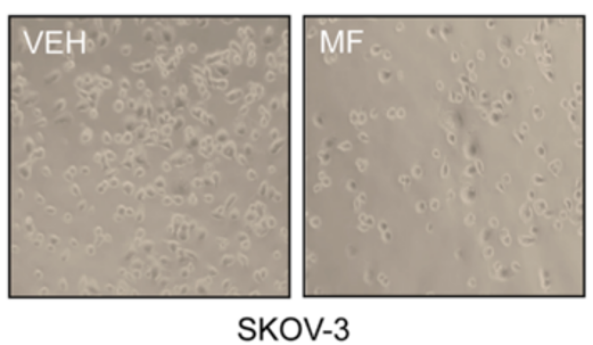

Figure 7 Mifepristone-pretreated MDA-MB-231 (A), U87MG (B), LNCaP (C), and SKOV-3 (D) cells have delayed adhesion to extracellular matrix proteins. For all cell lines, treatment with cytostatic concentrations of mifepristone was administered for $72 \mathrm{~h}$ prior to plating. After treatment, cells were trypsinized and re-plated in a pre-coated plate at a density of 100,000 cells per well. FN: fibronectin, Col I: collagen I, Col IV: collagen IV, LN: Laminin, FG: Fibrinogen. Data shown in A-D represent one experiment that was repeated three times with a similar outcome. In E, SKOV-3 cells were cultured in the presence of vehicle (VEH) or mifepristone (MF) for $72 \mathrm{~h}$. The cells were trypsinized and placed in plates that had been pre-coated with $0.1 \%$ fibronectin or bovine serum albumin (BSA) used as a negative control of adhesion. Adhesion was quantified as the number of cells attached per $20 \mathrm{X}$ microscopic field. ${ }^{*} \mathrm{p}<0.05 \mathrm{vs}$. VEH; ${ }^{* *} p<0.01$ vs. VEH. Statistical analysis was done using two-way ANOVA followed by Bonferroni's post-test. Bright field Images in $\mathbf{F}$ are representative of vehicle (VEH) or mifepristone (MF)-pretreated cells observed after 60 min of incubation (200 X).

adherence of SKOV-3 cells to fibronectin. Figure 7F depicts representative bright field images of vehicle- or mifepristone-pretreated SKOV-3 cells that had attached to a fibronectin-coated surface for $60 \mathrm{~min}$; it can be clearly observed the reduced number of adhered cells that had been pre-treated with mifepristone (Figure 7, right panel) when compared to those exposed only to vehicle (Figure 7, left panel).

\section{Discussion}

In this study we observed that, at known cytostatic doses, mifepristone induced a strikingly similar change in shape of four highly metastatic and aggressive cancer cell lines. This included shrinkage of the cell body with long, thin, neurite-like cellular extensions. Morphology changes were found to be dependent on time of exposure to the drug, with confirmed and observable phenotypic changes occurring after $48 \mathrm{~h}$. These alterations were not influenced by the cellular density of culture, suggesting that mifepristone has an intrinsic effect upon cellular structure, and that this change in morphology is not a result of lack of perceived cell number. In addition, treatment with mifepristone was not associated with changes in total expression of $\beta$-actin and $\alpha$-tubulin. 
Mifepristone is known to exert anti-progestin activity by blocking the action of progesterone on progesterone receptors (PR) [34]. In cancer cells expressing high levels of PR, nanomolar concentrations of mifepristone have been shown to be sufficient to block cell growth ([8] and references cited therein). In the present work, in cell lines not expressing canonical PR [26], we used concentrations of mifepristone in the micromolar range, higher than those required to bind $\mathrm{PR}$, suggesting that a different mechanism not involving classical PR is at work. Such mechanism, which still needs to be unveiled, may be relevant to target with mifepristone cancers not expressing standard PR.

Potential mediators of the effect of mifepristone are the glucocorticoid receptors (GR). It was reported that mifepristone binds GR when used at concentrations higher than those needed to bind PR [35]. We previously addressed that the only commonality among the four cell lines studied in the present work was the expression of the beta isoform of the GR (GR- $\beta$ ) [26]. This is of interest as GR- $\alpha$ is considered the driver of glucocorticoid effects upon regulation of gene transactivation, whereas GR- $\beta$ has been mostly considered a dominant negative isoform [36]. There are however reports indicating that in cells forced to express only GR- $\beta$, mifepristone was the only one out of more than 50 steroids capable of binding the receptor [37] and of regulating the activity of a reporter gene [38].

When operating at micromolar concentrations, mifepristone has a distinctive effect not shared by other natural and synthetic steroids. For instance, when used at equimolar concentrations, mifepristone was a much potent inhibitor of ovarian cancer cell growth than progesterone, medroxyprogesterone acetate or levonorgestrel [17]. Furthermore, equimolar concentrations of the GR agonist dexamethasone did not inhibit growth when compared to mifepristone or to two other related antiprogestins, ORG31710 and CDB2914 [39]. At the concentration utilized, dexamethasone was able to down regulate the expression of GR- $\alpha$ and GR- $\beta$ isoforms, whereas the antiprogestins did not, suggesting that they have different mechanisms of action despite reaching the cells at micromolar levels [39].

Important in studying mifepristone as a possible treatment option in oncology was to address its long-term effect on the cancer cells. Interestingly, upon removal of mifepristone following exposure for 3 days, cell morphology and proliferation returned to that of untreated cells in all cell lines except for the LNCaP prostate cancer cells. In these cells, the non-proliferative effect of mifepristone remained as long as 9 days following treatment removal, suggesting an irreversible growth arrest. Previous research has shown the propensity of LNCaP cells to enter irreversible growth arrest and senescence in response, for instance, to treatment with doxorubicin or to culture in androgen-free media [29,40]. We confirmed that $\mathrm{LNCaP}$ cells exposed to mifepristone become senescent upon removal of the drug as indicated by the increase in the activity of perinuclear SA- $\beta$-galactosidase. One possible explanation as to why, from a panel of 4 cells lines, only LNCaP cells underwent senescence following mifepristone, relies in the likely induction of the tumor suppressor gene $\mathrm{p} 16^{\mathrm{Ink} 4 \mathrm{~A}}$. While SKOV-3 and U87MG cell lines are null for p16 ${ }^{\text {Ink4A }}$ [41-43], and MDA-MB-231 has a homozygous deletion of p16 $6^{\text {Ink4A }}[44,45]$, LNCaP cells retain the $\mathrm{p} 16^{\mathrm{Ink} 4 \mathrm{~A}}$ gene [46]. Cells that undergo senescence have been reported to upregulate $\mathrm{p} 16^{\text {Ink4A }}$ [47-49], and not to regrow in response to overexpression of oncogenic Ras [50]. The phenomenon of senescence has been studied both in vitro and in vivo, and pro-senescence therapy has rapidly become a target for cancer treatment [51]. Whereas it was shown that senescence occurs naturally in benign tumors of melanocytes [52], it was also found that cellular senescence can be induced in vivo and block, for example, prostate tumorigenesis [53]. Also, the use of chemotherapy to induce senescence has been shown to be successful in mice models, leading to an anti-tumor effect with a corresponding increase in p16 ${ }^{\text {Ink4A }}$ [54]. The ability of mifepristone to induce senescence in $\mathrm{p} 16^{\text {Ink4A }}$-positive prostate cancer cells provides yet another rationale for its potential use as an anti-cancer agent, in particular in cells carrying wild type versions of the $\mathrm{p} 16^{\text {Ink4A }}$ tumor suppressor gene.

An alternative explanation for the senescence induced by mifepristone in LNCaP cells is the possible mediation by androgen receptors (ARs). LNCaP is the only cell line in the studied cohort that expresses ARs [26], which have been found able to bind mifepristone [55]. Thus, the role of both p16 ${ }^{\text {Ink4A }}$ as well as ARs in the mediation of mifepristone-induced senescence in LNCaP cells deserves to be investigated.

Mifepristone likely altered cellular morphology as a consequence of the dysregulation of the cytoskeletal structure, which was observed via fluorescent staining of actin fibers (F-actin) and tubulin filaments; these were both found to rearrange in response to mifepristone. Actin fibers were found reorganized to sites located at the ends of tubulin-rich extensions. As this was seen multiple times in different directions within individual cells, there appears to be a loss of cell polarity following mifepristone treatment. Upon mifepristone treatment, tubulin filaments were mainly located in the neurite-like extensions, in contrast to their original localization throughout the cell body with particular intensity around the nucleus observed in controls.

F-actin is formed by polymerization of actin molecules that assemble at different times and locations, depending upon the extracellular environment [32]. These actin- 
based structures interact with one another or with microtubule-based structures, reflecting the complexity of the dynamics of the cytoskeleton [56]. Among the actin-based structures are: i) cortical actin, which mostly defines the shape of the cell; ii) finger-like protrusions termed filopodia that are adhered in some manner to a substratum or another cell, and are believed to function as directional sensors; iii) stress fibers that are contractile actomyosin bundles essential for cell adhesion to the substratum and for changes in cell morphology during migration; iv) lamellipodia, which are surface-attached sheet-like, membrane protrusions with weak adherence, and observed during cell motility and spreading; and v) ruffles, which are sheet-like membrane protrusions or flat membrane folds from the cortical cytoskeleton that do not attach whatsoever to the extracellular matrix. Ruffles are formed as a consequence of inefficient integrinligand interaction at the leading edge of lamellipodia and contain densely packed arrays of thin actin filaments [33]. A high frequency of ruffle formation is usually associated with low lamellipodia formation and inefficient cell adhesion and migration [33]. We propose that mifepristone induces the accumulation of membrane ruffles and a reduction in lamellipodia, thus destabilizing the formation of cell substrate adhesions by integrins that connect the cytoskeleton with the extracellular matrix [57]. Under mifepristone treatment, the formation of adhesions may be inefficient because lamellipodia may not have the appropriate anchorage, becoming detached and retracted toward the main cell body, thus forming membrane ruffles. The behavior of mifepristone-treated cells supports the data of Born et al. [33], suggesting that high ruffling rates are indicative of inadequate adhesion, whereas low ruffling rates are associated with optimal adhesion. While the majority of nascent adhesions undergo rapid turnover such that their components can be incorporated into newly formed adhesion sites, a few mature behind the leading edge in response to tensile stress and increase in size [58]. Adhesion turnover may be blocked by mifepristone leading to the accumulation of actin ruffles that mature and do not adhere to the substratum. We suggest that the more ruffles, the less surface area mifepristone-treated cells would have to actually develop the needed focal adhesion complexes to link the cytoskeleton, the integrins and the extracellular matrix.

We observed that cells under the stress of mifepristone are easily de-adhered from the extracellular surface than untreated cells when exposed to a sub-optimal concentration of trypsin. Because an inverse relationship between de-adhesion time and cell contractility assessed by trypsininduced de-adhesion has been demonstrated [59], by altering cytoskeletal dynamics, mifepristone may interfere with the molecular link between the actin cytoskeleton and the extracellular matrix. In addition, owing to the fact that changes in shape and cytoskeletal remodeling are coupled to the cell cycle machinery governing the G1/S transition [60-62], it is possible that the cell growth inhibition caused by mifepristone, which we previously demonstrated to be associated with G1-S cell cycle arrest, blockage of cyclin dependent kinase 2 activity, and accumulation of cyclin dependent kinase inhibitors $\mathrm{p} 27^{\mathrm{kip} 1}$ and $\mathrm{p} 21^{\mathrm{cip} 1}[14,17,26]$, may be secondary to a primary effect on the cytoskeleton.

Since the survival, movement and invasiveness of cancer cells in the organism require great plasticity in the distribution of F-actin, our data suggest the mifepristone may interfere with such actin polymerization dynamics, disturbing the metastatic process. Blocking actin plasticity with mifepristone can be therapeutically beneficial to reduce the seeding at secondary sites by cells that had detached from a primary tumor.

Microtubules are important to maintain cell shape, play a key role in the polarized distribution of signals within a cell, and have been implicated in the asymmetric regulation of adhesion dynamics; in particular, they promote adhesion disassembly triggering the destabilization first, and then the detachment of adhesion components. At the same time, adhesions can be pulled off the substrate by stress fibers, which contract in response to microtubule depolymerization [27]. We observed a lack of radial distribution of tubulin filaments from the center of the cells in response to mifepristone; instead we visualized an increase of tubulin fibers located in the neurite-like extensions of the cells where the membrane actin ruffles became abundant, suggesting a connection between redistribution of microtubules and dysregulated adhesion. Usually an intact microtubule network with dynamic properties that are asymmetric has the full potential to coordinate adhesion dynamics in different regions of the cells, allowing directional migration [27]. Mifepristone may disrupt this dynamic equilibrium, blocking adhesion dynamics, and, tentatively, migration as well. Further studies are necessary to elucidate the relationship between mifepristone treatment, membrane ruffling, tubulin rearrangement, and cellular adhesion.

\section{Conclusions}

The anti-cancer effect of mifepristone manifested in the inhibition of cellular growth is related to drastic alternations in cellular morphology with the formation of neurite-like protrusions and altered cytoskeletal architecture characterized by an increase in membrane F-actin ruffling and concentration of tubulin filaments at the neurite-like cellular extensions. Such effect of mifepristone is associated with dysregulated cellular adhesion; it is reversible in most cell lines, except for prostate cancer cells that instead undergo senescence. Whether or not mifepristone-induced cytostasis, and alterations in cell shape, cytoskeletal structure, and 
adhesion capacity affect the migratory and invasive properties of cancer cells, warrant further investigations.

\section{Additional files}

Additional file 1: Figure S1. Time-course effect of mifepristone on cancer cells of the ovary (A), breast (B), prostate (C), and nervous system (D). Cells were seeded at a density appropriate for exponential growth for each cell line, allowed to adhere for $24 \mathrm{~h}$, and then exposed to a previously determined cytostatic concentration of mifepristone (MF) for $72 \mathrm{~h}$. Cells that received vehicle for $72 \mathrm{~h}$ were used as positive control of growth (right panel, VEH). Images were taken using phase contrast microscopy every $12 \mathrm{~h}$ and examined for morphological changes. Scale bar $=50 \mu \mathrm{m}$.

Additional file 2: Figure S2. Treatment of SKOV-3 cells with mifepristone induced inhibition of growth associated with changes in cell morphology. Cells were cultured in 8-well chamber slides in the presence of vehicle (VEH) or $20 \mu \mathrm{M}$ mifepristone (MF) for 4 days. At the end of the incubation cells were fixed with $4 \%$ paraformaldehyde and stained with hematoxylin. X 400

Additional file 3: Figure S3. Long-term effect of mifepristone on LNCaP cells. Cells were seeded, allowed to adhere for $24 \mathrm{~h}$, and then exposed to a cytostatic concentration of mifepristone (MF) for $72 \mathrm{~h}$. Thereafter, triplicate wells were harvested by trypsinization and counted by microcytometry. Remaining wells were returned to vehicle treatment and monitored after 1, 3, 7, or 9 days for their growth in the absence of MF and compared against the growth of similar number of cells never exposed to the steroid.

Additional file 4: Figure S4. Effect of mifepristone on the cellular distribution of filamentous actin (F-actin) and tubulin. SKOV-3 cells, U87MG, MDA-MB-231 and LNCaP were cultured in the presence of vehicle (VEH) or mifepristone (MF) for $72 \mathrm{~h}$, following which immunocytochemistry was used to visualize the cytoskeletal protein atubulin, AlexaFluor $594^{\circledR}$ phalloidin was used to visualize filamentous actin (F-actin), and DAPI to label cell nuclei. Images were taken using confocal microscopy. Scale bar $=50 \mu \mathrm{m}$.

Additional file 5: Figure S5. Expression of $\beta$-actin and a-tubulin in mifepristone-treated cells. Cells were plated and exposed to either vehicle (VEH) or the cytostatic concentration of mifepristone (MF) optimized previously for each cell line for $72 \mathrm{~h}$. Following treatment, cells were subsequently harvested, lysed, and whole-protein extracts, representing equal numbers of VEH or MF-treated cells were separated by electrophoresis. Immunoblots were then probed for $\beta$-actin and atubulin. GAPDH was included as a loading control. Densitometry analysis was performed from three different experiments and protein levels expressed as the ratio of $\beta$-actin/GAPDH (A), or a-tubulin/GAPDH (B). Densitometry graphs represent the mean \pm s.e.m.

Additional file 6: Table S1. Semi-quantitative representation of the effect of mifepristone on the adhesion of cells to individual extracellular matrix proteins.

\section{Competing interests}

The authors declare that there is no conflict of interest that could influence the impartiality of the research reported.

\section{Authors' contributions}

Conceived and designed experiments: BNB AAG CMT. Performed experiments BNB CRT TMU MST AAG. Analyzed the data: BNB AAG CMT. Contributed reagents/materials/analysis tools: CMT. Wrote the paper: BNB CMT. All authors read and approved the final manuscript.

\section{Acknowledgments}

This study was supported by National Cancer Institute Grant K22CA121991, ARRA Supplement K22CA121991-S1, and R15CA164622 (to CMT) and in part by a South Dakota Board of Regents competitive research grant award (SDBOR/USD 2011-10-06) (to CMT), and funds from the Division of Basic Biomedical Sciences, Sanford School of Medicine (to AAG). BNB and CRT were recipients of graduate student scholarships from the University of South Dakota. MST was a recipient of a summer medical student research scholarship from the Sanford School of Medicine.

Received: 24 May 2012 Accepted: 24 January 2013

Published: 26 January 2013

\section{References}

1. Fedele L, Berlanda N: Emerging drugs for endometriosis. Expert Opin Emerg Drugs 2004, 9(1):167-177.

2. Kettel LM, Murphy AA, Morales AJ, Yen SS: Preliminary report on the treatment of endometriosis with low-dose mifepristone (RU 486). Am J Obstet Gynecol 1998, 178(6):1151-1156.

3. Eisinger SH, Meldrum S, Fiscella K, le Roux HD, Guzick DS: Low-dose mifepristone for uterine leiomyomata. Obstet Gynecol 2003, 101(2):243-250.

4. Murphy AA, Morales AJ, Kettel LM, Yen SS: Regression of uterine leiomyomata to the antiprogesterone RU486: dose-response effect. Fertil Steril 1995, 64(1):187-190.

5. Steinauer J, Pritts EA, Jackson R, Jacoby AF: Systematic review of mifepristone for the treatment of uterine leiomyomata. Obstet Gynecol 2004, 103(6):1331-1336.

6. Matsuda Y, Kawamoto K, Kiya K, Kurisu K, Sugiyama K, Uozumi T: Antitumor effects of antiprogesterones on human meningioma cells in vitro and in vivo. J Neurosurg 1994, 80(3):527-534.

7. Jurado R, Lopez-Flores A, Alvarez A, Garcia-Lopez P: Cisplatin cytotoxicity is increased by mifepristone in cervical carcinoma: an in vitro and in vivo study. Oncol Rep 2009, 22(5):1237-1245.

8. Lanari C, Wargon V, Rojas P, Molinolo AA: Antiprogestins in breast cancer treatment: are we ready? Endocr Relat Cancer 2012, 19(3):R35-R50.

9. Heikinheimo O, Hsiu JG, Gordon K, Kim S, Williams RF, Gibbons WE, Hodgen GD: Endometrial effects of RU486 in primates-antiproliferative action despite signs of estrogen action and increased cyclin-B expression. J Steroid Biochem Mol Biol 1996, 59(2):179-190.

10. Narvekar N, Cameron S, Critchley HO, Lin S, Cheng L, Baird DT: Low-dose mifepristone inhibits endometrial proliferation and up-regulates androgen receptor. J Clin Endocrinol Metab 2004, 89(5):2491-2497.

11. Schneider CC, Gibb RK, Taylor DD, Wan T, Gercel-Taylor C: Inhibition of endometrial cancer cell lines by mifepristone (RU 486). J Soc Gynecol Investig 1998, 5(6):334-338.

12. Moe BT, Vereide AB, Orbo A, Jaeger R, Sager G: Levonorgestrel, medroxyprogesterone and progesterone cause a concentrationdependent reduction in endometrial cancer (Ishikawa) cell density, and high concentrations of progesterone and mifepristone act in synergy. Anticancer Res 2009, 29(4):1047-1052.

13. Rose FV, Barnea ER: Response of human ovarian carcinoma cell lines to antiprogestin mifepristone. Oncogene 1996, 12(5):999-1003.

14. Goyeneche AA, Seidel EE, Telleria CM: Growth inhibition induced by antiprogestins RU-38486, ORG-31710, and CDB-2914 in ovarian cancer cells involves inhibition of cyclin dependent kinase 2. Invest New Drugs 2012, 30(3):967-980.

15. Freeburg EM, Goyeneche AA, Telleria CM: Mifepristone abrogates repopulation of ovarian cancer cells in between courses of cisplatin treatment. Int J Oncol 2009, 34(3):743-755.

16. Freeburg EM, Goyeneche AA, Seidel EE, Telleria CM: Resistance to cisplatin does not affect sensitivity of human ovarian cancer cell lines to mifepristone cytotoxicity. Cancer Cell Int 2009, 9:4.

17. Goyeneche AA, Caron RW, Telleria CM: Mifepristone inhibits ovarian cancer cell growth in vitro and in vivo. Clin Cancer Res 2007, 13(11):3370-3379.

18. Li DQ, Wang ZB, Bai J, Zhao J, Wang Y, Hu K, Du YH: Effects of mifepristone on invasive and metastatic potential of human gastric adenocarcinoma cell line MKN-45 in vitro and in vivo. World 」 Gastroenterol 2004, 10(12):1726-1729.

19. El Etreby MF, Liang Y, Johnson MH, Lewis RW: Antitumor activity of mifepristone in the human LNCaP, LNCaP-C4, and LNCaP-C4-2 prostate cancer models in nude mice. Prostate 2000, 42(2):99-106.

20. El Etreby MF, Liang Y, Lewis RW: Induction of apoptosis by mifepristone and tamoxifen in human LNCaP prostate cancer cells in culture. Prostate 2000, 43(1):31-42. 
21. Check JH, Sansoucie L, Chern J, Amadi N, Katz Y: Mifepristone treatment improves length and quality of survival of mice with spontaneous leukemia. Anticancer Res 2009, 29(8):2977-2980.

22. Check JH, Sansoucie L, Chern J, Dix E: Mifepristone treatment improves length and quality of survival of mice with spontaneous lung cancer. Anticancer Res 2010, 30(1):119-122.

23. Check JH, Dix E, Cohen R, Check D, Wilson C: Efficacy of the progesterone receptor antagonist mifepristone for palliative therapy of patients with a variety of advanced cancer types. Anticancer Res 2010, 30(2):623-628.

24. Kimmick GG, Muss HB: Endocrine therapy in metastatic breast cancer. Cancer Treat Res 1998, 94:231-254.

25. Gamarra-Luques CD, Goyeneche AA, Hapon MB, Telleria CM: Mifepristone prevents repopulation of ovarian cancer cells escaping cisplatinpaclitaxel therapy. BMC Cancer 2012, 12:200.

26. Tieszen CR, Goyeneche AA, Brandhagen BN, Ortbahn CT, Telleria CM: Antiprogestin mifepristone inhibits the growth of cancer cells of reproductive and non-reproductive origin regardless of progesterone receptor expression. BMC Cancer 2011, 11:207.

27. Broussard JA, Webb DJ, Kaverina I: Asymmetric focal adhesion disassembly in motile cells. Curr Opin Cell Biol 2008, 20(1):85-90.

28. Valastyan S, Weinberg RA: Tumor metastasis: molecular insights and evolving paradigms. Cell 2011, 147(2):275-292.

29. Pernicova Z, Slabakova E, Kharaishvili G, Bouchal J, Kral M, Kunicka Z, Machala M, Kozubik A, Soucek K: Androgen depletion induces senescence in prostate cancer cells through down-regulation of Skp2. Neoplasia 2011, 13(6):526-536.

30. Waterman-Storer CM, Salmon WC, Salmon ED: Feedback interactions between cell-cell adherens junctions and cytoskeletal dynamics in newt lung epithelial cells. Mol Biol Cell 2000, 11(7):2471-2483.

31. Watanabe T, Noritake J, Kaibuchi K: Regulation of microtubules in cell migration. Trends Cell Biol 2005, 15(2):76-83.

32. Chhabra ES, Higgs HN: The many faces of actin: matching assembly factors with cellular structures. Nat Cell Biol 2007, 9(10):1110-1121.

33. Borm B, Requardt RP, Herzog V, Kirfel G: Membrane ruffles in cell migration: indicators of inefficient lamellipodia adhesion and compartments of actin filament reorganization. Exp Cell Res 2005, 302(1):83-95.

34. Rauch $M$, Loosfelt $H$, Philibert D, Milgrom E: Mechanism of action of an antiprogesterone, RU486, in the rabbit endometrium. Effects of RU486 on the progesterone receptor and on the expression of the uteroglobin gene. Eur J Biochem 1985, 148(2):213-218.

35. Moguilewsky M, Philibert D: RU 38486: potent antiglucocorticoid activity correlated with strong binding to the cytosolic glucocorticoid receptor followed by an impaired activation. J Steroid Biochem 1984, 20(1):271-276.

36. Yudt MR, Jewell CM, Bienstock RJ, Cidlowski JA: Molecular origins for the dominant negative function of human glucocorticoid receptor beta. $\mathrm{Mol}$ Cell Biol 2003, 23(12):4319-4330.

37. Lewis-Tuffin LJ, Jewell CM, Bienstock RJ, Collins JB, Cidlowski JA: Human glucocorticoid receptor beta binds RU-486 and is transcriptionally active. Mol Cell Biol 2007, 27(6):2266-2282.

38. Kino T, Manoli I, Kelkar S, Wang Y, Su YA, Chrousos GP: Glucocorticoid receptor (GR) beta has intrinsic, GRalpha-independent transcriptional activity. Biochem Biophys Res Commun 2009, 381(4):671-675.

39. Telleria CM, Goyeneche AA: Antiprogestins in ovarian cancer. In Ovarian Cancer - Clinical and Therapeutic Perspectives. Edited by Farghaly S. Rijeka, Croatia: Intech; 2012:207-230.

40. Ewald J, Desotelle J, Almassi N, Jarrard D: Drug-induced senescence bystander proliferation in prostate cancer cells in vitro and in vivo. Br J Cancer 2008, 98(7):1244-1249.

41. Kawakami Y, Hama S, Hiura M, Nogawa T, Chiba T, Yokoyama T, Takashima S, Tajiri H, Eguchi K, Nagai N, et al: Adenovirus-mediated p16 gene transfer changes the sensitivity to taxanes and Vinca alkaloids of human ovarian cancer cells. Anticancer Res 2001, 21(4A):2537-2545.

42. Wang Y, Zhu S, Cloughesy TF, Liau LM, Mischel PS: p53 disruption profoundly alters the response of human glioblastoma cells to DNA topoisomerase I inhibition. Oncogene 2004, 23(6):1283-1290.

43. Weller M, Rieger J, Grimmel C, Van Meir EG, De Tribolet N, Krajewski S, Reed JC, von Deimling A, Dichgans J: Predicting chemoresistance in human malignant glioma cells: the role of molecular genetic analyses. Int J Cancer 1998, 79(6):640-644.
44. Hui R, Macmillan RD, Kenny FS, Musgrove EA, Blamey RW, Nicholson Rl, Robertson JF, Sutherland RL: INK4a gene expression and methylation in primary breast cancer: overexpression of p16INK4a messenger RNA is a marker of poor prognosis. Clin Cancer Res 2000, 6(7):2777-2787.

45. Musgrove EA, Lilischkis R, Cornish AL, Lee CS, Setlur V, Seshadri R, Sutherland RL: Expression of the cyclin-dependent kinase inhibitors p16INK4, p15INK4B and p21WAF1/CIP1 in human breast cancer. Int J Cancer 1995, 63(4):584-591.

46. Lu S, Tsai SY, Tsai MJ: Molecular mechanisms of androgen-independent growth of human prostate cancer LNCaP-Al cells. Endocrinology 1999, 140(11):5054-5059.

47. Alcorta DA, Xiong Y, Phelps D, Hannon G, Beach D, Barrett JC: Involvement of the cyclin-dependent kinase inhibitor p16 (INK4a) in replicative senescence of normal human fibroblasts. Proc Natl Acad Sci U S A 1996, 93(24):13742-13747.

48. Hara E, Tsurui H, Shinozaki A, Nakada S, Oda K: Cooperative effect of antisense-Rb and antisense-p53 oligomers on the extension of life span in human diploid fibroblasts, TIG-1. Biochem Biophys Res Commun 1991 179(1):528-534.

49. Shay JW, Pereira-Smith OM, Wright WE: A role for both RB and p53 in the regulation of human cellular senescence. Exp Cell Res 1991, 196(1):33-39.

50. Beausejour CM, Krtolica A, Galimi F, Narita M, Lowe SW, Yaswen P, Campisi J: Reversal of human cellular senescence: roles of the p53 and p16 pathways. EMBO J 2003, 22(16):4212-4222.

51. Nardella C, Clohessy JG, Alimonti A, Pandolfi PP: Pro-senescence therapy for cancer treatment. Nat Rev Cancer 2011, 11(7):503-511.

52. Michaloglou C, Vredeveld LC, Soengas MS, Denoyelle C, Kuilman T, van der Horst CM, Majoor DM, Shay JW, Mooi WJ, Peeper DS: BRAFE600-associated senescence-like cell cycle arrest of human naevi. Nature 2005, 436(7051):720-724

53. Chen Z, Trotman LC, Shaffer D, Lin HK, Dotan ZA, Niki M, Koutcher JA, Scher $\mathrm{HI}$, Ludwig T, Gerald W, et al: Crucial role of p53-dependent cellular senescence in suppression of Pten-deficient tumorigenesis. Nature 2005, 436(7051):725-730

54. Schmitt CA, Fridman JS, Yang M, Lee S, Baranov E, Hoffman RM, Lowe SW: A senescence program controlled by $\mathrm{p} 53$ and p16INK4a contributes to the outcome of cancer therapy. Cell 2002, 109(3):335-346.

55. Song LN, Coghlan M, Gelmann EP: Antiandrogen effects of mifepristone on coactivator and corepressor interactions with the androgen receptor. Mol Endocrinol 2004, 18(1):70-85.

56. Stricker J, Falzone T, Gardel ML: Mechanics of the F-actin cytoskeleton. J Biomech 2010, 43(1):9-14

57. DeMali KA, Burridge K: Coupling membrane protrusion and cell adhesion. J Cell Sci 2003, 116(Pt 12):2389-2397.

58. Bershadsky AD, Balaban NQ, Geiger B: Adhesion-dependent cell mechanosensitivity. Annu Rev Cell Dev Biol 2003, 19:677-695.

59. Sen S, Kumar S: Cell-matrix De-adhesion dynamics reflect contractile mechanics. Cell Mol Bioeng 2009, 2(2):218-230

60. Mammoto A, Huang S, Moore K, Oh P, Ingber DE: Role of RhoA, mDia, and ROCK in cell shape-dependent control of the Skp2-kip1 pathway and the G1/S transition. J Biol Chem 2004, 279(25):26323-26330.

61. Mammoto A, Ingber DE: Cytoskeletal control of growth and cell fate switching. Curr Opin Cell Biol 2009, 21(6):864-870.

62. Assoian RK, Klein EA: Growth control by intracellular tension and extracellular stiffness. Trends Cell Biol 2008, 18(7):347-352.

doi:10.1186/1471-2407-13-35

Cite this article as: Brandhagen et al:: Cytostasis and morphological changes induced by mifepristone in human metastatic cancer cells involve cytoskeletal filamentous actin reorganization and impairment of cell adhesion dynamics. BMC Cancer 2013 13:35 